EGU2020-18677

https://doi.org/10.5194/egusphere-egu2020-18677

EGU General Assembly 2020

(c) Author(s) 2021. This work is distributed under

the Creative Commons Attribution 4.0 License.

\title{
Climate SMART Agriculture: How well does the agricultural sector in Luxembourg perform in terms of climate change?
}

\author{
Evelyne Stoll ${ }^{1}$, Christian Schader ${ }^{2}$, Torsten Bohn ${ }^{3}$, Rachel Reckinger ${ }^{4}$, Laura Leimbrock ${ }^{1}$, Gilles \\ Altmann ${ }^{1}$, and Stéphanie Zimmer ${ }^{1}$ \\ ${ }^{1}$ Insitute for Organic Agriculture Luxembourg (IBLA), Research \& Development, Luxembourg (stoll@ibla.lu) \\ ${ }^{2}$ Research Institute of Organic Agriculture (FiBL) \\ ${ }^{3}$ Luxembourg Institute of Health, Department of Population Health (LIH) \\ ${ }^{4}$ University of Luxembourg (UL)
}

In Luxembourg, the agricultural sector was responsible for $711.7 \mathrm{Gg} \mathrm{CO}_{2}$-equivalents in 2016, which corresponds to $6.95 \%$ of the total country greenhouse gas (GHG) emissions. Over $50 \%$ of the farms are specialist grazing livestock farms. The beef and cattle milk production account globally together for over $60 \%$ of the sector's global emissions. Thus, the climate impact of the whole agricultural sector in Luxembourg can be significantly lowered by reducing the GHG emissions of the specialist grazing livestock sector. However, beyond farm type, the GHG emissions of a farm are also influenced by other factors, such as management systems and farming practices. To enable a transition towards a more climate-positive agriculture, insights into the sustainability performance in terms of climate change are needed.

The aim of this study is to determine the current sustainability performance of the Luxembourgish specialist grazing livestock sector in terms of climate change. The climate impact of the different specialist grazing livestock farm types (OTE (orientation technico-économique) 45 - Specialist dairying; OTE 46 - Specialist cattle - rearing and fattening and OTE 47 - Cattle - dairying, rearing and fattening combined) and of different management systems (conventional or organic) was assessed at farm-level. Furthermore, the relationship between the sustainability performance in terms of climate change and other areas of sustainability is being studied. Farming practices of 60 farms typical for Luxembourg in regard to their share of arable land and permanent grassland (OTE 45: 3 farms; OTE 46: 15; OTE 45: 11; Conventional: 44; Organic: 16) and their respective sustainability implications were assessed in 2019 according to the FAO SAFA Guidelines (Guidelines for the Sustainability Assessment of Food and Agriculture Systems, 2014) using the Sustainability Monitoring and Assessment RouTine (SMART)-Farm Tool (v5.0). Organic farms were highly overrepresented, with $26.7 \%$ in the sample compared to $5 \%$ of all Luxembourgish farms. The data was collected during a farm visit and a $3 \mathrm{~h}$ interview with the farm manager. The impact of management system and farm type on the SAFA-goal achievement for the sub-theme Greenhouse Gases (GHG) were studied.

The results show that the sustainability performances of the participating farms were moderate to 
good. Goal achievement for the sub-theme GHG was moderate and did not differ significantly between the three farm types (OTE 45: $53.3 \% \pm 3.9$ SD goal achievement; OTE $46: 55.6 \% \pm 7.3$ SD; OTE 47: $54.6 \% \pm 6.9$ SD). Organic farms showed a significantly higher mean goal achievement for GHG than conventional farms (p-value < 0.001) (organic: $58.3 \% \pm 6.0$ SD; conventional: $52.6 \% \pm 4.4$ SD). For indicators positively impacting GHG, the organic and the OTE 46 farms had generally higher ratings. Correlations between GHG and the other sub-themes were mainly in the Environmental Integrity dimension, showing that implementing climate-positive farming practices can also improve other ecological aspects. The indicator analysis identified the following linchpins: increase in protein autarky, closing of farming cycles and holistic approach with strategic decision making leading to harmonized actions towards a sustainable and climate positive farming system. 